\title{
Sexual Violence among Married Women: Burden and Action Taken
}

\author{
Shakuntala Chhabra, Anu Namgyal, Swati Tyagi \\ Department of Obstetrics and Gynecology, Mahatma Gandhi Institute of Medical Sciences, Sevagram, Wardha, Maharashtra, India
}

\section{A B S T R A C T}

Background: Sexual violence (SV) is a public health concern world-wide. The present study used World Health Organization definition "SV is serious public health human rights problem with short- and long-term consequences on women's physical, mental, sexual, reproductive health. Whether SV occurs in context of intimate partnership, within larger family or community structure, or during times of conflict, it is deeply violating painful experience for survivor." Aim: The present study was aimed to look into magnitude of SV among married women. Subjects and Methods: It was cross-sectional study conducted in Rural Institution of Central India. The study subjects were married women, who reported to gynecological out-patient for some ailments or friends or relatives of patients, mostly from villages. They were interviewed in an area with privacy with pre-designed questionnaire in local language by social worker and their answers were recorded. Informed consent was obtained and confidentiality was assured. Results: Of 2000 interviewed, 675 (34.7\%) had suffered SV. One hundred thirty six ( $7 \%$ interviewed, $20.2 \%$ sufferers), reported they were forced to have sex with person other than husbands. Eighteen (1.4\%) reported sexual advances made toward them at work places. Thirty-four ( $5 \%$ of 675 ) had been forced by their own husbands and/or family members to have sex with other persons, 4 (0.6\%) forced to have sex with husbands against their wishes, $373(55.3 \%)$ were subjected to hurting sex, $232(34.4 \%)$ to unusual sex, 26 (3.9\%) others were dissatisfied for other reasons. Of all sufferers, 5.3\% had reported to police, 451 (61.5\%) not spoken to anyone. Most had not sought medical services. Consumption of alcohol/drugs, poverty were reported risk factors. Conclusion: Women continue to suffer SV irrespective of economic class, education. For prevention, broader coalition between communities health services is needed by integration into reproductive health services. Providers need to be trained to support sufferer, women need to be aware of services.

KEY WORDS: Health services, sexual violence, women

\section{BACKGROUND}

Sexual violence (SV), the manifestation of social, psychological, and economic subordination of women, has existed since ancient times, but has remained largely hidden. It is now being recognized as important public health concern world-wide carce, mostly incomplete studies indicate that SV is commonly a component of intimate partner violence (IPV). Much of the information, which comes from the police and health services, is under estimates, since only small fraction of women who experience SV reach these services. Available literature reveals that in some countries such as Africa, Ireland, nearly one of four women suffer SV by intimate partner and up to one-third adolescent girls report forced sexual initiation. ${ }^{[1-5]}$ It could be that it is more prevalent in low resource settings due to lack of education, information,

\begin{tabular}{|l|l|}
\hline \multicolumn{2}{|c|}{ Access this article online } \\
\hline Quick Response Code & Website: \\
\hline 回 & www.jbcrs.org \\
\cline { 2 - 2 } & \\
\hline
\end{tabular}

cultural differences and that women are not aware of their rights. Despite its prevalence, it has received relatively less attention from the social scientists, practitioners, justice system and the society as a whole. SV as marital rape continues to be debated and women continue to suffer. In World Health Organization (WHO) definition of SV "SV is a serious public health and human rights problem with both short- and long-term consequences on women's physical, mental, and sexual and reproductive health. Whether SV occurs in the context of an intimate partnership, within the larger family or community structure, or during times of conflict, it is a deeply violating and painful experience for the survivor" was used. ${ }^{[6]}$

Research is essential to understand the subject in depth for implementation of policies, which will further lead to prevention and better care of victims. The present study was aimed to look into the magnitude of SV among married women in low resource settings.

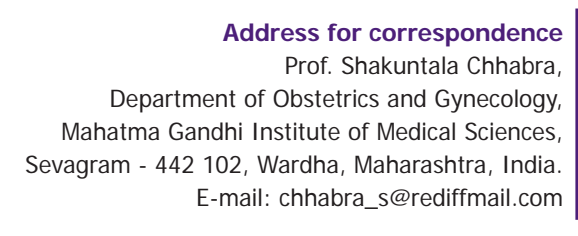

Address for correspondence Prof. Shakuntala Chhabra, Department of Obstetrics and Gynecology, ma Gandhi Institute of Medical Sciences, E-mail: chhabra_s@rediffmail.com 


\section{SUBJECTS AND METHODS}

It was a cross-sectional, anonymous study conducted in a Rural Institution of Central India over a period of 1 year. The authors endeavored to look into the issue of SV in women of the area with limited resources. Study subjects (2000 married women) were randomly included every tenth woman who visited gynecological out-patient, (health seekers, their friends or relatives) irrespective of socio-economic class or any other reason, if they were willing. They were interviewed by a social worker with the help of a pre-designed questionnaire in local language with privacy. Social worker was briefed about the objective of the study and the methodology. Study subjects were informed the objectives of the study. Informed consent was taken and confidentially was assured. Questions were asked verbally and recorded on the questionnaire by the social worker who had asked the questions.

\section{RESULTS}

Out of the 2000 women interviewed, 675 (34.7\%) reported SV, of the 42 teenagers 9 (21.4\%), 374 (34.6\%) of 1082 between 20 and 29 years, 173 (37.8\%) of 458 women between 30 and 39 years and 99 (29.5\%) of 336 between 40 and 49 years [Table 1]. Out of 229 illiterate women $63(27.5 \%), 88(32.8 \%)$ of 274 undergraduates and $32(41 \%)$ of 78 postgraduates studied interviewed reported SV.

Of 370 laborers interviewed, 108 (29.19\%) reported having suffered SV, $80(40 \%)$ of 200 other working women, $253(37.4 \%)$ of 677 housewives reported having suffered SV [Table 2].

One hundred thirty six (20.1\%) of all women interviewed had reported that they were forced by persons other than their own husbands to have sex with them, brother-in-law 32, father-in-law 32, strangers 34 , and 38 by others. Eighteen $(1.4 \%)$ women reported sexual advances made at their work places. Thirty four women (1.7\%) reported that they had been forced by husbands and/or family members to have sex with other person (15 by husbands, 12 by father-in-law, 6 brother-in-law, and 1 by employer). Of 2000 women, $1273(65.3 \%)$ said that they were satisfied with their sexual life, but 675 (34.7\%) were not and 52 did not reply. Of 675 women, $4(0.6 \%)$ said that they were not satisfied as they were forced to have sex against their wishes, 373 (55.3\%) women were subjected to hurting sex, 18 (2.7\%) reported too little sex, 22 (3.3\%) reported too frequent sex, 232 (34.4\%) were subjected to unusual sex and $26(3.9 \%)$ were dissatisfied for other reasons. In general, study subjects said that consumption of alcohol, drugs and poverty were risk factors as they thought that SV was because of these factors.

\begin{tabular}{|c|c|c|c|c|c|c|c|}
\hline \multicolumn{8}{|c|}{$\begin{array}{c}\text { Table 1: Age, occupation of women who had suffered sexual } \\
\text { violence }\end{array}$} \\
\hline \multirow[t]{2}{*}{ Occupation } & \multirow[t]{2}{*}{ Violence } & \multicolumn{6}{|c|}{ Age in years } \\
\hline & & $<20$ & $20-29$ & $30-39$ & $40-49$ & $>50$ & Total \\
\hline \multirow[t]{6}{*}{ Laborer 370} & Yes & & & & & & \\
\hline & No. & 02 & 58 & 25 & 18 & 05 & 108 \\
\hline & $\%$ & 25 & 29 & 29.4 & 99 & 33.3 & 29.2 \\
\hline & No & & & & & & \\
\hline & No. & 06 & 142 & 60 & 44 & 10 & 262 \\
\hline & $\%$ & 75 & 71 & 70.6 & 71 & 66.7 & 70.8 \\
\hline \multirow[t]{6}{*}{ Farmer 553} & Yes & & & & & & \\
\hline & No. & 04 & 103 & 44 & 32 & 07 & 190 \\
\hline & $\%$ & 33.3 & 34.4 & 34.6 & 34.4 & 31.8 & 34.34 \\
\hline & No & & & & & & \\
\hline & No. & 08 & 196 & 83 & 61 & 15 & 363 \\
\hline & $\%$ & 66.7 & 65.6 & 65.4 & 65.6 & 68.2 & 65.6 \\
\hline \multirow[t]{6}{*}{ Service/business 375} & Yes & & & & & & \\
\hline & No. & 03 & 67 & 28 & 21 & 05 & 124 \\
\hline & $\%$ & 37.5 & 33 & 32.9 & 33.3 & 31.3 & 33.1 \\
\hline & No & & & & & & \\
\hline & No. & 05 & 136 & 57 & 42 & 11 & 251 \\
\hline & $\%$ & 62.5 & 67 & 67.1 & 66.7 & 68.8 & 66.9 \\
\hline \multirow[t]{6}{*}{ Housewives 677} & Yes & & & & & & \\
\hline & No. & 05 & 137 & 58 & 43 & 10 & 253 \\
\hline & $\%$ & 35.7 & 37.4 & 37.4 & 37.7 & 35.7 & 37.4 \\
\hline & No & & & & & & \\
\hline & No. & 09 & 229 & 97 & 71 & 18 & 424 \\
\hline & $\%$ & 64.2 & 62.6 & 62.6 & 62.3 & $64 \cdot 3$ & 62.2 \\
\hline \multirow[t]{3}{*}{ Others 25} & No & & & & & & \\
\hline & No. & - & 14 & 06 & 04 & 01 & 25 \\
\hline & $\%$ & - & 100 & 100 & 100 & 100 & 100 \\
\hline \multirow[t]{6}{*}{ Total 2000} & Yes & & & & & & \\
\hline & No. & 09 & 374 & 173 & 99 & 20 & 675 \\
\hline & $\%$ & 21.42 & 34.6 & 37.8 & 29.5 & 24.4 & 33.8 \\
\hline & No & & & & & & \\
\hline & No. & 33 & 708 & 285 & 237 & 62 & 1325 \\
\hline & $\%$ & 78.6 & 65.4 & 62.2 & 70.5 & 75.6 & 66.3 \\
\hline \multicolumn{8}{|l|}{ Grand total } \\
\hline & No. & 42 & 1082 & 458 & 336 & 82 & 2000 \\
\hline & $\%$ & 2.1 & 54.1 & 22.9 & 16.8 & 4.1 & 100 \\
\hline
\end{tabular}

Of 675 women who had suffered SV, only $5.3 \%$ had reported to police. Reasons for not talking to anyone varied, $451(61.5 \%)$ did not speak due to fear and 171 (25.3\%) were too embarrassed to report to anyone.

\section{DISCUSSION}

$\mathrm{SV}$ is increasingly being recognized, however many women neither inform police nor seek medical services due to known, unknown reasons even though they are at risk of suffering long-term problems. The stigma that many victims face, plunges them into a resigned silence, which hinders possible help and masks the burden of the problem. ${ }^{[7]}$ Hence, several health care models are being evolved to maximize the medical response to SV. ${ }^{|8|}$

In the present study, though nearly $35 \%$ married women had reported having suffered SV, only $5.3 \%$ of them had reported to police. According to WHO survey (2013), prevalence of SV was 29.8\% in America, 36.6\% in African region, 25.4\% in European region and $37.7 \%$ in South East Asia region. ${ }^{|9|}$ In a study by Schei et al. ${ }^{[10]}$ only $10 \%$ SV victims had reported to post-rape services. It may be lack of awareness, fear 


\begin{tabular}{|c|c|c|c|c|c|c|c|c|}
\hline \multirow[t]{2}{*}{ Occupation } & \multirow[t]{2}{*}{ Violence } & \multicolumn{7}{|c|}{ Education } \\
\hline & & Illiterate & $1-4^{\text {th }}$ & $5-8^{\text {th }}$ & $9-12^{\text {th }}$ & UG & PG & Total \\
\hline \multirow[t]{6}{*}{ Laborer 370} & Yes & & & & & & & \\
\hline & No. & 12 & 13 & 14 & 50 & 15 & 04 & 108 \\
\hline & $\%$ & 28.6 & 29.5 & 28.6 & 29.4 & 29.4 & 28.6 & 29.2 \\
\hline & No & & & & & & & \\
\hline & No. & 30 & 31 & 35 & 120 & 36 & 10 & 262 \\
\hline & $\%$ & 71.4 & 57.4 & 71.4 & 70.6 & 70.6 & 71.4 & 70.8 \\
\hline \multirow{6}{*}{ Farmer 553} & Yes & & & & & & & \\
\hline & No. & 22 & 23 & 25 & 87 & 26 & 7 & 190 \\
\hline & $\%$ & 34.4 & 34.8 & 44.7 & $34 \cdot 3$ & 34.2 & 33.3 & 34.4 \\
\hline & No & & & & & & & \\
\hline & No. & 42 & 43 & 47 & 167 & 50 & 14 & 363 \\
\hline & $\%$ & 65.6 & 65.9 & 65.3 & 65.7 & 65.8 & 66.7 & 65.6 \\
\hline \multirow[t]{6}{*}{ Service/business 375} & Yes & & & & & & & \\
\hline & No. & 14 & 15 & 16 & 57 & 17 & 5 & 124 \\
\hline & $\%$ & 32.6 & 33.3 & 84.2 & 33.1 & 33.3 & 33.3 & 33.1 \\
\hline & No & & & & & & & \\
\hline & No. & 29 & 30 & 3 & 115 & 34 & 10 & 251 \\
\hline & $\%$ & 67.4 & 66.7 & 15.8 & 66.9 & 66.7 & 66.7 & 66.9 \\
\hline \multirow{6}{*}{ Housewives 677} & Yes & & & & & & & \\
\hline & No. & 29 & 30 & 33 & 116 & 35 & 10 & 253 \\
\hline & $\%$ & 37.6 & 37 & 37.5 & $37 \cdot 3$ & 37.6 & 37 & 37.8 \\
\hline & No & & & & & & & \\
\hline & No. & 48 & 51 & 55 & 195 & 58 & 17 & 424 \\
\hline & $\%$ & 62.3 & 63 & 62.5 & 62.7 & 62.4 & 63 & 62.2 \\
\hline \multirow[t]{6}{*}{ Others 25} & Yes & & & & & & & \\
\hline & No. & - & - & - & - & - & - & - \\
\hline & $\%$ & - & - & - & - & - & - & - \\
\hline & No & & & & & & & \\
\hline & No. & 03 & 03 & 03 & 12 & 03 & 01 & 25 \\
\hline & $\%$ & 100 & 100 & 100 & 100 & 100 & 100 & 100 \\
\hline \multirow[t]{6}{*}{ Total 2000} & Yes & & & & & & & \\
\hline & No. & 63 & 104 & 105 & 283 & 88 & 32 & 675 \\
\hline & $\%$ & 27.5 & 43.5 & 40.2 & 30.8 & 32.1 & 41 & 33.8 \\
\hline & No & & & & & & & \\
\hline & No. & 166 & 135 & 156 & 636 & 186 & 46 & 1325 \\
\hline & $\%$ & 72.5 & 56.5 & 59.8 & 69.2 & 67.9 & 59 & 66.3 \\
\hline \multicolumn{9}{|l|}{ Grand total } \\
\hline & No. & 229 & 239 & 261 & 919 & 274 & 78 & 2000 \\
\hline & $\%$ & 11.5 & 12 & 13.1 & 46 & 13.7 & 03.1 & 100 \\
\hline
\end{tabular}

or inhibition due to social structure of society. Further psychological IPV is as detrimental as physical IPV, with the exception of effects on suicidality. ${ }^{[1]}$ According to Bennice et al., ${ }^{[12]} \mathrm{SV}$ severity explains a significant proportion of variance in post-traumatic stress disorders. These findings have important implications for mental health and also for social service professionals who work with battered women. Health care providers need to be aware of the problem. Health care settings could be the places where women are made aware of prevention of SV, their rights, sequlae. There is need of centers which offer $24 \mathrm{~h}$ services, forensic evidence collection and documentation as well as comprehensive medical treatment including psychological support follow-up. ${ }^{[10]}$

SV may involve torture and/or "perverse" sexual acts and are often physically violent. In the present study, 375 (55.5\%) women said they were hurt, $15.65 \%$ of all interviewed reported having been tortured and $11.6 \%$ reported perversion. It has also been reported that some husbands threaten to have relations with other women or demand that their wives return to their parents. ${ }^{[13]}$ Though women had suffered irrespective of age, education, percentage is more among educated women, probably illiterate women do not even understand that they are being violated. There are reports of marital rape regardless of age, social class, race or ethnicity. ${ }^{[14]}$

Overall of 2000 interviewed, assault by stranger was reported by $1.7 \%$ ( $5 \%$ of those who had suffered SV). When perpetrator is a stranger, woman is more likely to report the police, and less likely if perpetrator is known, especially husband. In study by Schei et al. ${ }^{[10]}$ intimate partner was rarely reported as perpetrator. This is in contrast to findings from a population-based study in which an intimate partner was by far the most common reported perpetrator. ${ }^{[15]}$ Study was conducted among newly married couples in Gujarat, India revealed $16 \%$ non-consensual marital sex, about a third of men confessed that they had forced sex on their wives. ${ }^{[16]}$ Women raped by their husbands hesitate to report due to family loyalty, fear of retribution, inability to leave relationship, or may not know that forced sex even in marriage is also rape. ${ }^{[17]}$ Physicians must ensure documentation of injuries to be able to help the sufferers.

In the present study, the reasons for not talking to anyone varied, $415(61.5 \%)$ did not speak to anyone due to fear, embarrassment was the reason given by 171 (25.3\%) women. Person who had assaulted was not ashamed, but sufferer was ashamed to speak about it is the irony!

Factors that increase a woman's vulnerability to SV vary from place to place. One study reports alcohol or drugs, use before sex, high number of sexual partners and poverty as risk factors ${ }^{[18]}$ and the same was reported by some women in the present study also.

Limitations of the present study were that only married women were selected for the interviews due to cultural reasons. Even in married women, we could not be sure, how many were actually telling the truth, again due to cultural reasons, fear and maybe other issues. However, as study has been done in a hospital setting, advantage is that women usually tell the truth, but the study subjects become limited.

Health sector should offer high-quality services, for documentation, gathering of evidence, emergency contraception, treatment for sexually transmitted infections, counseling and other psychosocial support required in long-term, there is need for collaboration between women's organizations, crisis-centers', as well as with police and legal systems. Reproductive health care providers are particularly well placed to detect sexual coercion to care for its predominantly female victims, since many women 
routinely visit health care settings for various reasons. Strengthening services for victims of violence benefit clients and staff becomes aware of need to protect patients' privacy and maintain the confidentiality of medical records.

Ultimately, aim should be prevention of SV, which requires involvement of a broader coalition including the media, schools, and communities.

\section{REFERENCES}

1. Marie-Antoinette S. Professional development: Gender inequality and lack of sexual and reproductive rights of women in Ghana: Implications for social work education. Int J Contin Social Work Educ 2007;10:26.

2. Yahaya I, Soares J, De Leon AP, Macassa G. A comparative study of the socioeconomic factors associated with childhood sexual abuse in sub-Saharan Africa. Pan Afr Med J 2012;11:51.

3. Panganai T, Samkange W. Sexual dilemma: Perceptions and attitudes of sexually violated women in Gweru Urban, Zimbabwe. Greener J Soc Sci 2013;3:349-63.

4. Bradley F, Smith M, Long J, O'Dowd T. Reported frequency of domestic violence: Cross sectional survey of women attending general practice. BMJ 2002;324:271.

5. Deyessa N, Berhane Y, Ellsberg M, Emmelin M, Kullgren G, Högberg U. Violence against women in relation to literacy and area of residence in Ethiopia. Glob Health Action 2010;3.

6. World Health Organization. Sexual violence. Sexual and reproductive health, 2002. Available from: http://www.who.int/reproductivehealth/ topics/violence/sexual_violence/en/. [Last accessed on 2014 Aprill].

7. Kim B. Nonconsensual sex undermines sexual health. Network $2005 ; 23: 4,3$.
8. Ashfored L. New population policies advancing women's health and rights. Population bulletin 2001;56:1.

9. Global and Regional Estimates of Violence against Women. Prevalence and Health Effects of Intimate Partner Violence and Non-Partner Sexual Violence. Sexual and Reproductive Health. WHO; 2013.

10. Schei B, Sidenius K, Lundvall L, Ottesen GL. Adult victims of sexual assault: Acute medical response and police reporting among women consulting a center for victims of sexual assault. Acta Obstet Gynecol Scand 2003;82:750-5.

11. Pico-Alfonso MA, Garcia-Linares MI, Celda-Navarro N, Blasco-Ros C, Echeburúa E, Martinez M. The impact of physical, psychological, and sexual intimate male partner violence on women's mental health: Depressive symptoms, posttraumatic stress disorder, state anxiety, and suicide. J Womens Health (Larchmt) 2006;15:599-611.

12. Bennice JA, Resick PA, Mechanic M, Astin M. The relative effects of intimate partner physical and sexual violence on post-traumatic stress disorder symptomatology. Violence Vict 2003;18:87-94.

13. Bazargan-Hejazi S, Medeiros S, Mohammadi R, Lin J, Dalal K. Patterns of intimate partner violence: A study of female victims in Malawi. J Inj Violence Res 2013;5:38-50.

14. Faizal H, Khan ME, Townsend J. Marital sexual violence is 'a terrifying experience'. Network 2005;23:12.

15. Dobash RP, Dobash RE, Wilson M, Daly M. The myth of sexual symmetry in marital violence. Soc Probl 1992;39:71-91.

16. Khan ME, Townsend J, Sinha R, Lakhanpal S. Sexual violence within marriage. Seminar 1996;447:32-5.

17. Trish H. I was alive but not living. Network 2005;23:13.

18. Jewkes R, Sen P, Garcia-Moreno C. Sexual violence. In: World Report on Violence and Health. Geneva: WHO; 2002.

How to cite this article: Chhabra S, Namgyal A, Tyagi S. Sexual violence among married women: Burden and action taken. J Basic Clin Reprod Sci 2014;3:101-4.

Source of Support: Nil, Conflict of Interest: None declared

\section{Author Help: Reference checking facility}

The manuscript system (www.journalonweb.com) allows the authors to check and verify the accuracy and style of references. The tool checks the references with PubMed as per a predefined style. Authors are encouraged to use this facility, before submitting articles to the journal.

- The style as well as bibliographic elements should be $100 \%$ accurate, to help get the references verified from the system. Even a single spelling error or addition of issue number/month of publication will lead to an error when verifying the reference.

- Example of a correct style Sheahan P, O'leary G, Lee G, Fitzgibbon J. Cystic cervical metastases: Incidence and diagnosis using fine needle aspiration biopsy. Otolaryngol Head Neck Surg 2002;127:294-8.

- $\quad$ Only the references from journals indexed in PubMed will be checked.

- Enter each reference in new line, without a serial number.

- Add up to a maximum of 15 references at a time.

- If the reference is correct for its bibliographic elements and punctuations, it will be shown as CORRECT and a link to the correct article in PubMed will be given.

- If any of the bibliographic elements are missing, incorrect or extra (such as issue number), it will be shown as INCORRECT and link to possible articles in PubMed will be given. 